\title{
Gastro-intestinale Clostridium perfringens-infecties: een blijvend gevaar in de Belgische rundveehouderij
}

\author{
${ }^{1}$ B. Valgaeren, ${ }^{2}$ E. Goossens, ${ }^{2}$ S. Verherstraeten, ${ }^{1} \mathrm{~L}$. Gille, ${ }^{1} \mathrm{~L}$. Van Driessche, ${ }^{2} \mathrm{~F}$. Van Immerseel, \\ ${ }^{2}$ R. Ducatelle, ${ }^{1}$. Deprez, ${ }^{1}$ B. Pardon
}

${ }^{1}$ Vakgroep Inwendige Ziekten en Klinische Biologie van de Grote Huisdieren,

${ }^{2}$ Vakgroep Pathologie, Bacteriologie en Pluimveeziekten,

Faculteit Diergeneeskunde, Universiteit Gent,

Salisburylaan 133, B-9820 Merelbeke

Bonnie.Valgaeren@UGent.be

\section{AMENVATTING}

De intensivering van de moderne landbouw wordt geassocieerd met een toename van Clostridium perfringens-gerelateerde, gastro-intestinale problemen bij intensief gevoede runderen, zoals "hemorrhagic bowel disease" bij hoogproductief melkvee en enterotoxemie bij kalveren. Waar de pathogenese van hemorrhagic bowel disease nog grotendeels ongekend is, werden er de laatste jaren nieuwe inzichten in de pathogenese van enterotoxemie bekomen die een belangrijke repercussie op de aanpak van deze ziekte onder praktijkomstandigheden hebben. Ook andere clostridiumgeassocieerde maagdarminfecties, zoals "overeating disease" en neonatale clostridiose, worden regelmatig gediagnosticeerd. Overvoedering met structuurarme, eiwitrijke voeders is een overkoepelende risicofactor bij zowel HBD, enterotoxemie als overeating disease. Een goed uitgebalanceerd dieet dat zo stabiel mogelijk gehouden wordt, is dan ook het belangrijkste aandachtspunt op bedrijven die problemen hebben met clostridiose. Daarnaast dient bij jonge kalveren voldoende aandacht gegeven te worden aan een correcte en hygiënische biestverstrekking om problemen met neonatale clostridiose te vermijden.

\section{INLEIDING}

Heden worden een toenemende specialisatie van een exclusieve vlees- of melkproductie en een sterke schaalvergroting waargenomen (Landbouwrapport Vlaanderen, 2012). Deze specialisatie gaat gepaard met een intensivering, waarbij vaak zeer energie- en eiwitrijke diëten worden ingezet. Deze intensieve voederschema's, die zowel in de gespecialiseerde melk- als vleesveehouderij worden toegepast, predisponeren echter voor verschillende gastro-intestinale ziekten, waaronder clostridiuminfecties. Dit vertaalt zich in een verhoogde gevoeligheid voor onder andere "hemorrhagic bowel disease" (HBS) bij hoogproductief melkvee (Ceci et al., 2006; Elhanafy et al., 2013), en voor enterotoxemie bij vleesvee (Lebrun et al., 2010). In het bijzonder voor de praktiserende dierenarts wordt in dit overzichtsartikel een bondig overzicht gegeven van de pathogenese, symptomatologie, diagnose en preventie van de belangrijkste Clostridium perfringens-geassocieerde aandoeningen in de moderne rundveehouderij.
MICROBIOLOGISCHE EIGENSCHAPPEN VAN CLOSTRIDIUM PERFRINGENS

C. perfringens is een opportunistische bacterie en een onderdeel van de normale darmflora van gezonde runderen en kalveren, die onder bepaalde predisponerende omstandigheden ziekte kan veroorzaken. $C$. perfringens is een grampositieve, anaerobe kiem, die echter zeer zuurstoftolerant is en daardoor lang in de stalomgeving kan overleven (Hasal en Hall, 1975). Bovendien vormt de bacterie sporen die op hun beurt ook zeer resistent zijn tegen zuurstof, extreme temperaturen, UV-bestraling en de meeste ontsmettingsmiddelen (Shimizu et al., 2002; Hurst en Merchant, 2001; Orsburn et al., 2008; Doyle, 2002; Paredes-Sabja et al., 2008). Deze zeer resistente sporen zijn de belangrijkste infectieuze celtypes maar moeten omgezet worden naar vegetatieve kiemen in het spijsverteringsstelsel om te kunnen koloniseren en eventueel ziekte te veroorzaken (Hatheway, 1990). De kiem kent een zeer snelle groei en produceert alle enzymen die nodig zijn voor de glycolyse en het glycogeenmetabolisme, waardoor de aanwezigheid van suikers zelden een 
limiterende factor is voor de groei. Daarentegen heeft C. perfringens in vergelijking met andere bacteriën behoefte aan veel essentiële aminozuren, vitaminen en groeifactoren. De (over)groei van deze bacterie wordt dan ook hoofdzakelijk gelimiteerd door de aanwezigheid van voldoende eiwitten en groeifactoren en slechts in mindere mate door een teveel aan suikers of zetmeel (Fuchs en Bonde, 1957; Shimizu et al., 2002).

Vroeger werd de bacterie ingedeeld in vijf toxinotypes (A tot E), gebaseerd op de mogelijkheid van een bepaalde stam om één of meerdere van de vier "major toxines" te produceren. Deze "major toxines" zijn alfatoxine, bètatoxine, epsilon-oxine en iotatoxine (Niilo, 1980). Behalve deze "major toxines" is er echter een heel gamma aan "minor toxines" geidentificeerd, waarvan sommige eveneens een zeer belangrijke rol blijken te spelen in de pathogenese van verschillende dierziekten, bijvoorbeeld het netBtoxine bij necrotische enteritis bij vleeskuikens (Keyburn et al., 2008). Deze indeling in toxinotypes enkel gebaseerd op de productie van de "major toxines" is dus verouderd en kan in de meeste gevallen pathogene en niet-pathogene stammen niet onderscheiden. Bepaalde toxinen zijn consequent aanwezig bij elke stam, zoals onder andere alfatoxine en perfringolysine, terwijl andere toxinen slechts bij bepaalde stammen aanwezig zijn of tot expressie gebracht worden, zoals de andere "major toxines" of bijvoorbeeld het $\beta 2$ - en het netB-toxine.

\section{CLOSTRIDIUM PERFRINGENS-GEASSOCIEERDE GASTRO-INTESTINALE AANDOENINGEN BIJ RUN- DEREN}

Hieronder wordt een overzicht van de belangrijkste clostridium-geassocieerde darmontstekingen bij runderen gegeven.

\section{Hemorrhagic bowel disease}

\section{Klinische bevindingen}

Hemorrhagic bowel disease (HBS) is een opkomende ziekte bij voornamelijk volwassen melkvee en waarvan de exacte oorzaak nog niet is bekend (Godden et al., 2001; Forsberg et al., 2003; Socket et al., 2004; Abutarbush et al., 2004; Abutarbush en Radostitis, 2005; Ceci et al., 2006; Baines et al., 2011; Elhanafy et al., 2013). Op sommige Noord-Amerikaanse hoogproductieve melkveebedrijven is deze aandoening verantwoordelijk voor $30 \%$ van de totale uitval van lacterende koeien (Elhanafy et al., 2013). In onze streken wordt HBS minder gezien, alhoewel er ook een duidelijk toenemende incidentie lijkt te zijn. De ziekte wordt gekenmerkt door een acute, progressieve, segmentele necro-hemorragische darmontsteking proximaal in de dunne darm, waarbij in het lumen vaak bloedklonters worden gevonden (Figuur 1).
Dit leidt tot obstructies van het lumen, met klinische tekenen van mechanische ileus, zoals depressie, weinig mestpassage, sufheid, een opgezet abdomen, kolieksymptomen, anorexie, dehydratie, shock, een gedaalde melkgift en uiteindelijk sterfte. Op het rectale onderzoek zijn er ofwel geen afwijkingen, ofwel zijn er enkele opgezette dunne darmen. Op het echografisch onderzoek wordt er vaak een verminderde motiliteit van de dunne darmen opgemerkt en in sommige gevallen kunnen bloedklonters in het lumen van de darm gevisualiseerd worden (Abutarbush et al., 2004). De ziekte verloopt in sommige gevallen zeer acuut, waarbij plotse sterfte kan optreden zonder voorafgaande symptomen (Abutarbush en Radostitis, 2005; Ceci et al., 2006).

\section{Pathogenese}

HBS is typisch een voedingsgeassocieerde aandoening, die voornamelijk gezien wordt bij hoogproductieve melkkoeien, en met een speciale predispositie van het brownswiss-ras (Berghaus et al., 2005). De ziekte wordt het meest gezien in de herfst en de winter, bij oudere koeien vroeg in de lactatie (Berghaus et al., 2005). "Total mixed ration" (TMR)- diëten rijk aan energie en eiwit met weinig structuur hebben een predisponerend effect (Godden et al., 2001; Berghaus et al., 2005). De ziekte werd reeds geassocieerd met verschillende pathogenen, waaronder $C$. perfringens, maar ook met Aspergillus fumigatus, mycotoxinen en shigatoxine-producerende Escherichia coli's (ETEC's) (Forsberg, 2003; Socket, 2004; Elhanafy et al., 2013; Baines et al., 2011).

Er zijn een aantal overeenkomsten tussen HBS bij volwassen runderen en enterotoxemie bij kalveren. Zo zijn er gelijkaardige predisponerende factoren (intensieve voeding), het acute verloop van de ziekte en de aanwezigheid van een necro-hemorragische darmontsteking. Deze vaststelling draagt bij tot het vermoeden dat $C$. perfringens een belangrijke rol speelt in deze aandoening. Bovendien werd C. perfringens in hoge concentraties geïsoleerd uit aangetaste darmen (Ceci et al., 2006; Elhanafy et al., 2013). Een groot aantal van de geïsoleerde stammen bracht naast het alfatoxine echter ook het $\beta 2$-toxine tot expressie. Het aandeel van deze twee toxinen in de ontwikkeling van de geobserveerde letsels is echter tot op vandaag niet bekend. De overheersende hypothese betreffende de pathogenese van de ziekte is overvoeding met eiwit, met een bacteriële overgroei van $C$. perfringens, gevolgd door toxineproductie. Het alfatoxine zou dan kunnen leiden tot celschade en de productie van ontstekingsmediatoren, waardoor een lokale ontstekingsreactie in gang wordt gezet. In tegenstelling tot enterotoxemie bij kalveren, blijft de reactie bij HBS gelokaliseerd en veroorzaakt ze typisch segmentele hemorragische enteritis met bloedklonters in het lumen, terwijl bij kalveren een meer diffuus enteritisbeeld onstaat. Vervolgens komt het dier terecht in een vicieuze cirkel, waarbij de ontstekingsreactie de 


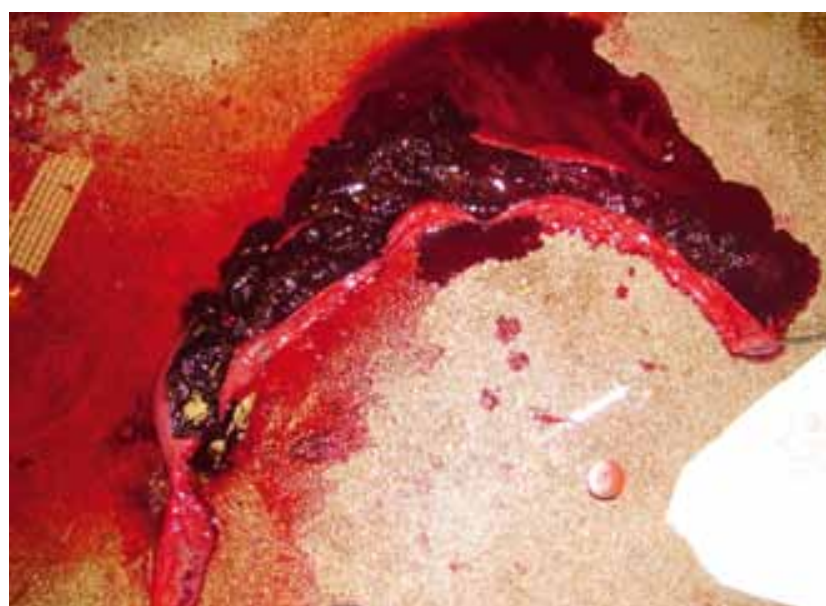

Figuur 1. Gereseceerd darmsegment (proximaal jejunum) van een rund met HBS, gevuld met bloedklonters (Foto: B. Valgaeren).

darmbarrière aantast, waardoor dan weer plasmaeiwitten en groeifactoren beschikbaar komen in het darmlumen voor bacteriële overgroei en kiemen en toxinen gemakkelijker in het weefsel diffunderen. Dit kan uiteindelijk leiden tot toxemie en sterfte (Elhanafy et al., 2013).

\section{Diagnose, behandeling en bestrijding}

Gezien de gebrekkige kennis van de pathogenese van de uitlokkende pathogenen, zijn geen eenduidige testen beschikbaar. De diagnose is dan ook vaak gebaseerd op de klinische bevindingen, echografie, autopsie en de uitsluiting van andere oorzaken van hemorragische enteritis, zoals salmonellose, boviene virale diarree virus (BVDV) en coccidiose. De letsels die gezien worden tijdens exploratieve laparotomie of lijkschouwing zijn zeer typisch. De behandeling van HBS gebeurt vaak chirurgisch door resectie van het aangetaste darmsegment (Figuur 2) of door het doormasseren van de bloedklonters. Er kan ook conservatief behandeld worden met antibiotica en prokinetica. De behandeling is zelden succesvol en de mortaliteit schommelt tussen 85 en 100\% (Kirkpatrick et al., 2001; Denisson et al., 2002; Peek et al., 2009; Braun et al., 2010). De aanpak van de ziekte dient dus volledig op preventie gericht te zijn door goed uitgebalanceerde diëten met voldoende structuur en geen hoge eiwitconcentraties. De vaccinatie met commercieel beschikbare vaccins of met autologe toxoïd vaccins is niet in staat om de incidentie van HBS op aangetaste bedrijven te verminderen (Elhafany et al., 2013).

\section{Enterotoxemie}

\section{Klinische bevindingen}

Enterotoxemie is een wijdverspreide, fatale darmontsteking bij jonge runderen. De ziekte komt voornamelijk voor in de eerste tien levensweken, hoewel ook

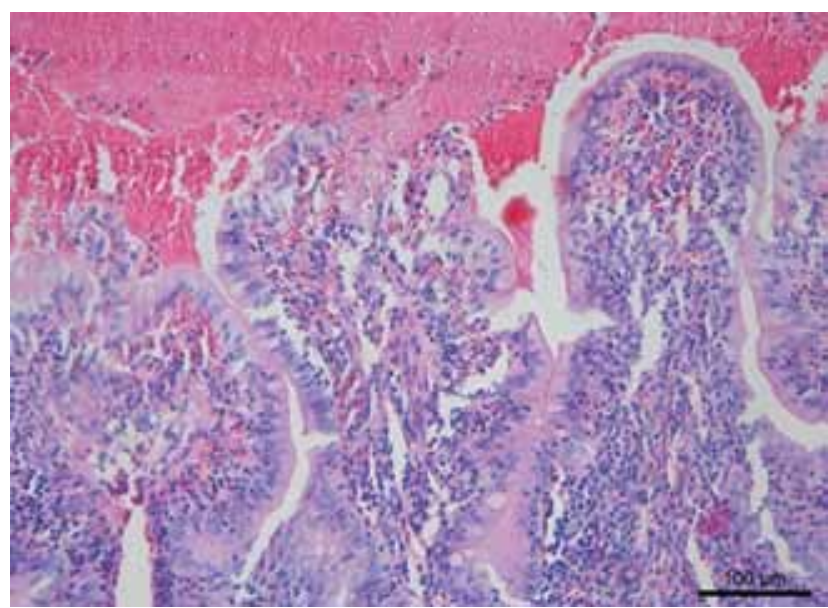

Figuur 2. Jejunum. Necrotische tippen van de villi met bloed in het darmlumen. H.E. 20x10. (Foto: K. Chiers).

oudere kalveren aangetast kunnen worden (Muylaert et al., 2010; Troxel et al., 1997). In het verleden werd deze ziekte voornamelijk gezien bij vleesrassen, met een hoge incidentie bij zoogkalveren (Griner en Bracken, 1953; Niilo et al., 1974). Vandaag wordt vooral een zeer hoge uitval ten gevolge van enterotoxemie gezien bij witvleeskalveren. Bij Belgisch witblauwe witvleeskalveren kan tot $20 \%$ van de totale mortaliteit aan deze ziekte toegewezen worden (Manteca et al., 2001; Pardon et al., 2012). In tegenstelling tot zoogkalveren wordt bij witvleeskalveren enterotoxemie vastgesteld in de hele productieronde met een piek rond 22 weken na de opzet (Pardon et al., 2012).

De ziekte verloopt steeds zeer acuut en de mortaliteit benadert 100\%. Vaak worden de kalveren dood aangetroffen zonder voorafgaande symptomen (Barkeret al., 1993). In een minderheid van de gevallen kan sterfte voorafgegaan worden door koliek, zenuwsymptomen en tekenen van agonie (Lebrun et al., 2010; Muylaert et al., 2010; Valgaeren et al., 2013a). Typisch voor de kadavers van kalveren die gestorven zijn aan clostridiose is een zeer snel postmortaal verval met opvallende tympanie van het abdomen (Figuur 3). Bij lijkschouwing wordt een segmentele of veralgemeende hemorragische ontsteking van de dunne darm met bloederige inhoud gezien (Lebrun et al., 2010; Manteca et al., 2002), alhoewel bijkomend ook andere darmsegmenten kunnen betrokken zijn (Figuur 4). Histologisch gaat de ziekte gepaard met een typerende necro-hemorragische enteritis met erosie van de darmvilli en necrose voornamelijk ter hoogte van de tippen van de darmvilli (Worrall et al., 1987; Manteca et al., 2002; Lebrun et al., 2010; Valgaeren et al., 2013b).

\section{Pathogenese}

Hoewel consequent de term enterotoxemie gebruikt wordt om deze ziekte te beschrijven, bestaat er controverse over de juistheid ervan. Tot op heden kon immers de aanwezigheid van de betrokken toxinen in 


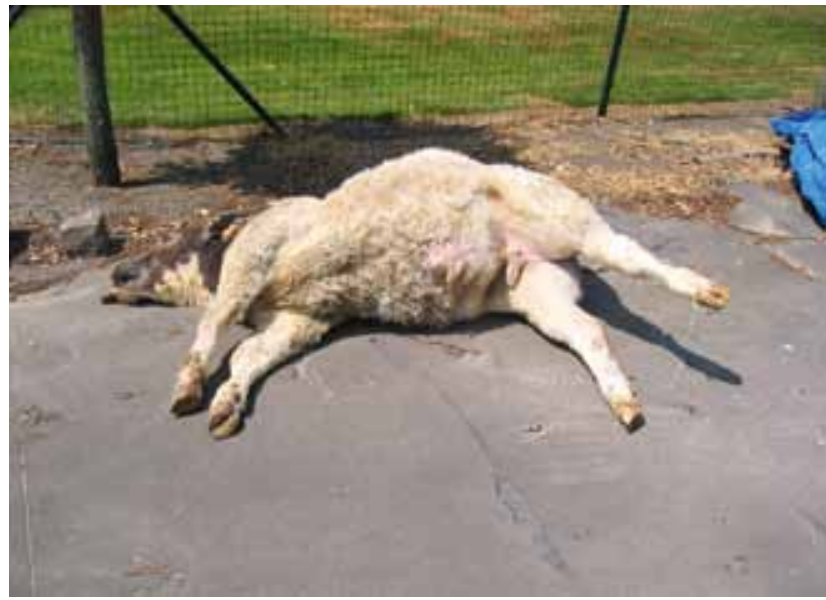

Figuur 3. Acute sterfte in een Belgisch witblauw kalf met opgezet abdomen en opvallende tympanie (Foto: $B$. Pardon).

de bloedbaan nooit worden aangetoond. Sommige auteurs spreken dan ook eerder van een $C$. perfringensgeassocieerde necrotische enteritis of hemorragische enteritis.

Recent onderzoek door de auteurs van het huidig artikel heeft enkele belangrijke inzichten in de pathogenese van deze opvallende ziekte opgeleverd. Waar tot enkele jaren geleden de rol van $C$. perfringens wel vermoed werd maar niet ontegensprekelijk bewezen was, kan nu met zekerheid gezegd worden dat zowel het alfatoxine als het perfringolysine een belangrijke rol speelt in de pathogenese van de ziekte (Songer, 1996; Manteca et al., 2001; Verherstraeten et al., 2013). Deze twee toxinen kunnen door elke stam geproduceerd worden, wat tot gevolg heeft dat elke $C$. perfringens-stam in principe het vermogen heeft om onder de juiste omstandigheden ziekte te induceren (Valgaeren et al., 2013b). Nochtans is $C$. perfringens een onderdeel van de normale microbiota bij gezonde kalveren. Onder normale omstandigheden wordt de overgroei van deze kiem geremd door de beperkte beschikbaarheid van nutriënten en door de aanwezigheid van een competitieve flora die een te sterke vermenigvuldiging van deze kiem verhindert door onder andere bacteriocineproductie. Vaak wordt enterotoxemie dan ook gezien na plotse voederwijzigingen of overvoedering, waarbij het normale evenwicht in de microbiota verstoord wordt (Lebrun et al., 2010).

Het zijn dan ook vooral deze predisponerende omstandigheden die de kans op ziekte bij een kalf bepalen en niet de aanwezigheid van $C$. perfringens in de stalomgeving of in de darmflora van het kalf. Wanneer $C$. perfringens samen met melkpoeder in het darmlumen wordt gebracht, predisponeert dit zeer sterk voor de inductie van necro-hemorragische letsels (Valgaeren et al., 2013a). Dit staaft de empirische bevinding dat wanneer een kalf in één voederbeurt zeer grote hoeveelheden melk opneemt, dit aanleiding kan geven tot het ontstaan van enterotoxemie. Een mogelijke verklaring hiervoor is de aanwezigheid van onverteerd melkeiwit in de dunne darm, wat een direct schadelijk effect kan hebben op de darmmucosa.

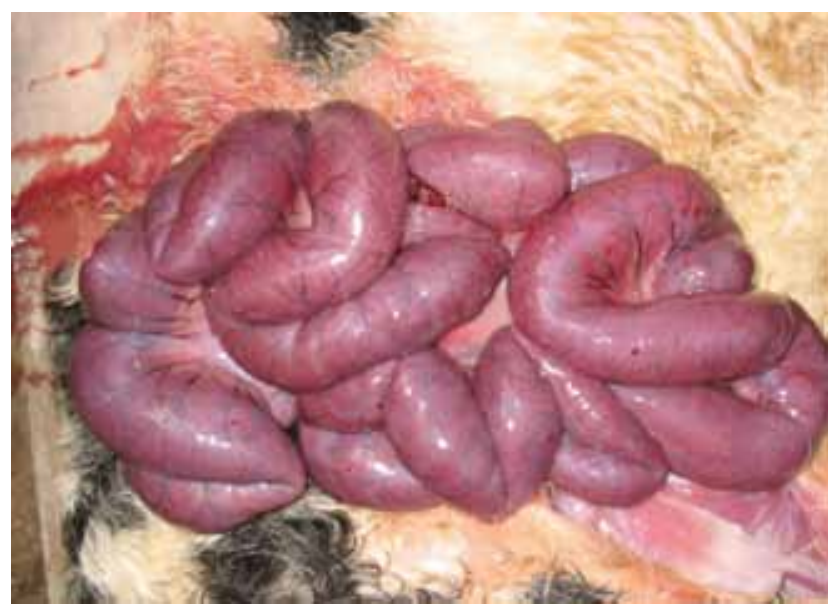

Figuur 4. Diffuse hemorragische enteritis bij een geval van enterotoxemia (Foto: B. Pardon).

Een overmatige beschikbaarheid van nutriënten kan hierbij uiteraard een belangrijke factor zijn (Annett et al., 2002). Ook directe effecten op de gastheer kunnen deze predispositie verklaren. Wanneer er schade optreedt aan de darmbarrière, bijvoorbeeld door aanwezigheid van andere noxen in het darmlumen, kunnen er plasma-eiwitten naar het darmlumen lekken, wat overgroei en toxineproductie in de hand kan werken. Bovendien leidt een verzwakte darmbarrière tot meer contact tussen alfatoxine en perfringolysine enerzijds en het onderliggende endotheel, de belangrijkste target van deze twee toxinen anderzijds (Verherstraeten et al., 2013). Dit leidt uiteindelijk tot necrose van de tippen van de darmvilli, waardoor de darmbarrière beschadigd wordt en het dier in een vicieuze cirkel terechtkomt, met onherroepelijk sterfte tot gevolg (Valgaeren et al., 2013).

\section{Diagnose en bestrijding}

De diagnose wordt meestal gesteld op basis van de bevindingen tijdens de lijkschouwing, maar in enkele gevallen kan een bevestiging van een klinisch vermoeden van enterotoxemie nodig zijn. In het verleden werd er vaak bacteriologisch onderzoek verricht van de darminhoud, waarbij het aantal clostridia gekwanticeerd werd. Recent onderzoek toonde echter aan dat zowel de sensitiveit als de specificiteit van deze techniek zeer laag is, wat verklaard kan worden door de zeer grote variabiliteit, de zeer snelle postmortale overgroei (*100 binnen 2 uur na sterfte) en de moeilijkheden bij de bewaring en cultuur van anaerobe kiemen. Deze techniek is dus van zeer weinig waarde in de diagnostiek van enterotoxemie (Valgaeren et al., 2013b). Ook toxinetypering van geïsoleerde stammen of toxinedetectietesten, zoals deze gebeuren voor ziekten die geïnduceerd worden door bètatoxine- of epsilontoxine-producerende stammen, is van weinig waarde voor het opsporen van enterotoxemie, omdat de belangrijkste betrokken toxinen (alfatoxine en perfringolysine) geproduceerd kunnen worden door alle C. perfringens-stammen (Verherstraeten et al., 
2013). Wel kan er verondersteld worden dat er hogere concentraties van deze toxinen worden bereikt in de darmen van aangetaste kalveren. Er zijn echter geen afkapwaarden bekend voor het tijdstip vanaf wanneer het vinden van alfatoxine (of perfringolysine) in de darminhoud als diagnostisch voor enterotoxemie kan worden beschouwd. De histologische letsels zijn vrij typisch en histologisch onderzoek van de darmen kan diagnostisch zijn. Een praktisch probleem is het zeer snelle postmortale verval van voornamelijk de mucosa van de darm, wat de interpretatie bemoeilijkt. Tot op heden zijn er dan ook geen afdoende betrouwbare laboratoriumtechnieken beschikbaar om een klinisch vermoeden van enterotoxemie te bevestigen. Een combinatie van de verschillende diagnostische testen is dan ook aangewezen om tot een zo betrouwbaar mogelijke conclusie te komen.

Gezien het zeer acute verloop van de ziekte en de hoge mortaliteit komt een curatieve behandeling steeds te laat. De bestrijding is dan ook volledig op preventie gericht. Net als voor andere perfringens-gerelateerde ziekten dient een evenwichtig, structuurrijk en vooral stabiel dieet centraal te staan in de preventie van enterotoxemie. Voornamelijk overvoedering met melk of melkvervangers blijkt een zeer belangrijke rol te spelen in de pathogenese en dient dus vermeden te worden (Lebrun et al., 2010; Valgaeren et al., 2013a). Door het voeren van kleinere porties kan darmstase en lebmaagovervloei vermeden worden, wat hypothetisch tot een verminderde kans op enterotoxemie kan leiden. Naast een goed voedermanagement kan ook het gebruik van pro- of prebiotica helpen om het evenwicht in de intestinale microbiota te bewaren en zo overgroei en toxineproductie te vermijden. Sommige prebiotica, bijvoorbeeld lookextracten, en probiotica, bijvoorbeeld Bifidobacter lactis, Lactobacillus rhamnosus, Bacillus subtilis, hebben rechtstreeks inhiberende effecten op C. perfringens (Collado et al., 2007; Jimoh et al., 2013; Lee et al., 2013). Er is een zeer grote variëteit aan producten op de markt en er zijn zeer weinig in-vivostudies uitgevoerd naar het gebruik van deze producten bij rundvee.

Een derde luik in de preventie van enterotoxemie

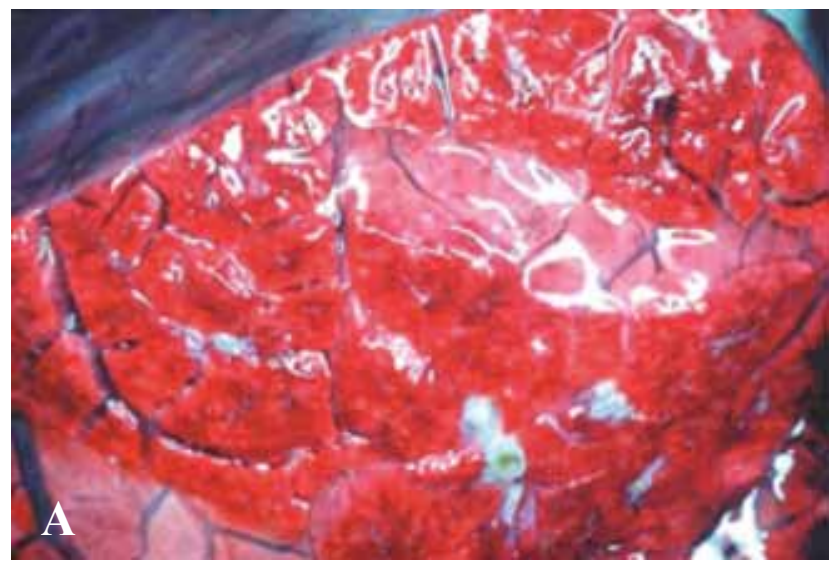

is het induceren van immuniteit bij de kalveren. Dit kan via natuurlijke weg of via vaccinatie. Recent werd in een studie aangetoond dat $80 \%$ van de kalveren die op jonge leeftijd gespeend werden en intensief gevoederd werden met een dieet bestaande uit ruw- en krachtvoer, spontaan hoge antistoffentiters produceerden tegen het alfatoxine. Hoewel niet specifiek aangetoond werd dat de aanwezigheid van deze antistoffen tegen enterotoxemie beschermt, werd binnen die populatie een lagere incidentie van enterotoxemie vastgesteld dan bij witvleeskalveren. Bij deze witvleeskalveren gevoederd met een hoofdzakelijk vloeibaar dieet van melkvervanger, ontwikkelde slechts $7 \%$ vergelijkbare titers. Het spenen op jonge leeftijd blijkt dus de ontwikkeling van een goede immuniteit tegen enterotoxemie in de hand te werken en kan daarom beschermend werken (Valgaeren et al., 2015b). Uiteraard kan er ook gebruik gemaakt worden van vaccinatie om immuniteit bij kalveren te induceren. In tegenstelling tot de situatie bij bètatoxine- of epsilontoxine-geïnduceerde aandoeningen, worden vanuit de praktijk teleurstellende resultaten gemeld van deze vaccinatie tegen enterotoxemie bij kalveren. Een mogelijke verklaring hiervoor is dat de commercieel beschikbare vaccins formaldehydegeïnactiveerde toxoïd bevatten. Deze manier van inactivatie tast de tertiaire eiwitstructuur aan, waardoor de geproduceerde antistoffen nauwelijks beschermen tegen het "wild-type" toxine (Goossens et al., 2015). Mogelijk is het minder stabiele alfatoxine gevoeliger voor deze structuuraantasting dan de andere toxinen, waardoor vaccinatie vaak tot teleurstellende resultaten leidt bij enterotoxemie (Songer, 1996; Goossens et al., 2015).

\section{"Overeating disease"}

Klinische bevindingen

Deze ziekte wordt vaak onder één noemer met enterotoxemie geplaatst, maar vertoont eigenlijk meer gelijkenissen met 'bloed' bij schapen. De ziekte wordt

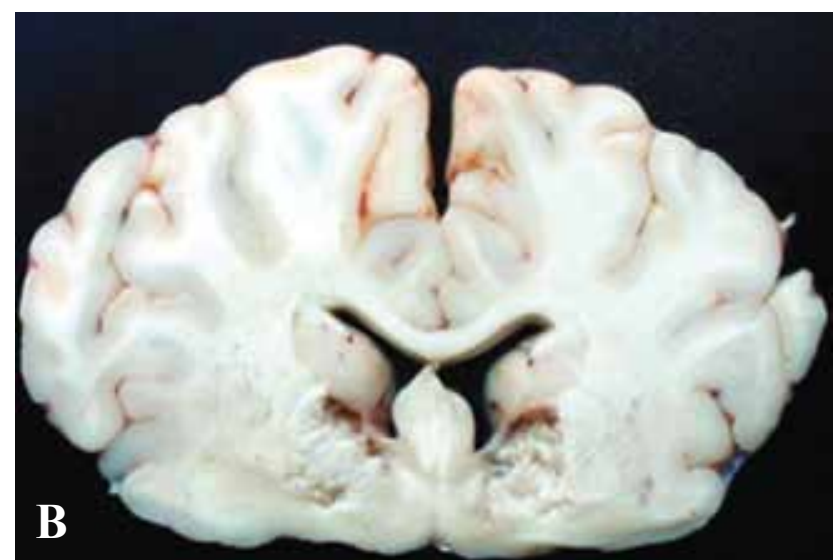

Figuur 5. Letsels bij kalveren die experimenteel geïnfecteerd werden met een epsilontoxine-producerende $C$. perfringensstam. A. Long met acuut longoedeem. B. Corpus striatum met focale, symmetrische encefalomalacia (Filho et al., 2009). 
meer gezien bij vleesrassen, hoewel er occasioneel ook uitbraken voorkomen bij intensief gevoederde kalveren van andere rassen. Zowel volwassen runderen (vooral in de afmestperiode), als kalveren kunnen aangetast worden. In tegenstelling tot enterotoxemie, gaat deze ziekte zelden gepaard met gastro-intestinale symptomen, maar eerder met ademhalingsproblemen en zenuwsymptomen, zoals acuut verlies van bewustzijn, hyperesthesie, intermitterende convulsies, decubitus en dyspneu (Niilo et al., 1963). Op lijkschouwing worden longoedeem en een typische focale, symmetrische encefalomalacie gezien (Griesemer en Krill, 1962; Filho et al., 2009) (Figuur 5).

\section{Pathogenese}

In tegenstelling tot necro-hemorragische enteritis die voornamelijk door alfatoxine en perfringolysine wordt veroorzaakt, wordt overeating disease veroorzaakt door het epsilontoxine. Dit toxine komt enkel voor bij toxinotypes B en D (Aichelman, 1956; Atkinson, 1998; Griesemer en Krill, 1962; Keast en McBarron, 1954). Het toxine wordt voornamelijk gevormd ter hoogte van het duodenum. Een overmaat aan nutriënten in dit darmsegment predisponeert dan ook voor overgroei en toxineproductie. Dit lijkt echter niet specifiek te zijn voor overeating disease en geldt waarschijnlijk voor de meeste $C$. perfringensgeassocieerde aandoeningen. Een te intensieve voeding is hier dan ook de belangrijkste risicofactor in de pathogenese van de ziekte. Daarnaast is het voorkomen van epsilontoxine-producerende stammen op een bedrijf een belangrijke risicofactor. In tegenstelling tot type A-stammen, die zeer algemeen voorkomen, komen toxinotype B en D minder algemeen voor. Een hoge infectiedruk van deze stammen kan bijdragen tot het ontstaan van uitbraken van de ziekte tijdens de afmestperiode van vleesvee (Niilo et al., 1963). Het epsilontoxine wordt geproduceerd in de darmen en wordt opgenomen in de bloedbaan, zodat men in dit geval van een echte enterotoxemie kan spreken. Vervolgens veroorzaakt het toxine perivasculair eiwitrijk oedeem, voornamelijk in de hersenen en in de longen, wat tot het typische ziektebeeld en de typische letsels leidt (Niilo et al., 1963).

\section{Diagnose en bestrijding}

De diagnose wordt meestal gesteld op basis van de typische klinische symptomen en letsels en kan bevestigd worden door de detectie van het epsilontoxine in de darminhoud, bloedbaan of weefsels van aangetaste dieren (Filho et al., 2009).

De belangrijkste preventiemaatregel is ook hier een goed uitgebalanceerde voeding, waarbij voldoende structuur wordt aangeboden zonder een grote eiwitovermaat (Niilo et al., 1963).

Net zoals bij kleine herkauwers kan ook bij runderen gevaccineerd worden tegen het epsilontoxine

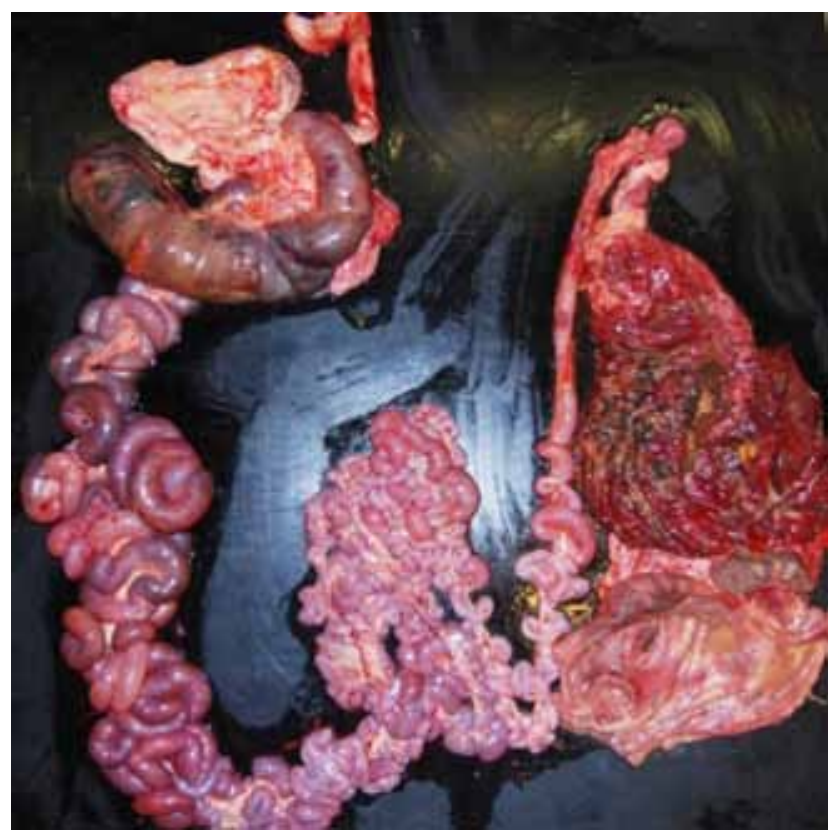

Figuur 6. Maagdarmstelsel van een kalf met necro-hemorragische abomaso-entero-tyflocolitis (Foto: B. Pardon).

met de commercieel beschikbare clostridiumvaccins. Hoewel er geen studies beschreven zijn waarin het effect van deze vaccinatie bij runderen onderzocht werd, werden bij enkele gerapporteerde gevallen uit de praktijk goede effecten van deze vaccinatie waargenomen; dit in tegenstelling tot de situatie bij enterotoxemie.

\section{Necrotische enteritis bij neonatale kalveren}

\section{Klinische bevindingen}

Net als de overige clostridium-geassocieerde aandoeningen, kent necrotische enteritis bij neonatale kalveren een zeer snel verloop. De ziekte wordt voornamelijk bij vleeskalveren van nul tot zeven dagen oud gezien die ofwel plots sterven, ofwel erg acute, vaak bloederige diarree vertonen. Andere klinische tekenen die met deze ziekte gepaard gaan, zijn anorexie, zwakte, sufheid, een opgezet abdomen en kolieksymptomen (Niilo et al., 1974; Garcia et al., 2013). De letsels situeren zich hoofdzakelijk (maar niet uitsluitend) in de dunne darmen die opvallend gestuwd of hemorragisch zijn. Naast de dunne darmen kunnen ook de pens, netmaaglebmaag, caecum en het colon aangetast zijn (Figuur 6). Histologisch worden een villusatrofie, diffuse bloedingen en een leukocyteninfiltratie gezien. Bijkomend kunnen segmentele necrotiserende vasculitis en fibrineuze trombi in de bloedvaten van de mucosa worden vastgesteld. Deze letsels zijn zeer sterk suggestief voor een clostridiuminfectie en kunnen dan ook als diagnostisch worden beschouwd. 


\section{Pathogenese}

De belangrijkste virulentiefactor van $C$. perfringens die geassocieerd wordt met deze ziekte is het bètatoxine, dat enkel voorkomt bij toxinotypes B en C. Dit toxine vormt poriën in de enterocyten, waardoor er darmnecrose ontstaat (Garcia et al., 2013). Bètatoxine is zeer gevoelig voor inactivatie door trypsine. Daarom wordt deze aandoening vooral bij neonatale dieren gezien, waarbij enerzijds de trypsine-inhibitor, aanwezig in colostrum, het bètatoxine beschermt tegen inactivatie door trypsine, en anderzijds het neonatale dier zelf lagere hoeveelheden trypsine produceert (Garcia et al., 2012). Neonatale dieren kunnen besmet worden met bètatoxine-producerende stammen uit een gecontamineerde omgeving, door contact met zieke dieren of asymptomatische uitscheiders (Garcia et al., 2013). Recent werd bovendien vastgesteld dat sondes en materiaal dat gebruikt wordt om biest te verschaffen, gecontamineerd kan worden met clostridiumsporen wanneer deze niet voldoende gereinigd en gedesinfecteerd worden (Valgaeren et al., 2015a).

De diagnose wordt meestal gesteld door het bevestigen van de aanwezigheid van het bètatoxine in de darminhoud (Garcia et al., 2012). Zoals hierboven beschreven kan ook histologisch onderzoek van de verse darm een grote hulp zijn in de diagnostiek van deze aandoening. Desinfectie van al het materiaal dat gebruikt wordt om biest te verschaffen met $3 \% \mathrm{H}_{2} \mathrm{O}_{2}$ oplossing na een grondige reiniging is voldoende om zowel sporen als vegetatieve kiemen van $C$. perfringens te doden en de kans op neonatale necrotische enteritis te verkleinen (Valgaeren et al., 2015a). In de praktijk wordt op bedrijven waar er problemen optreden met neonatale clostridiose vaak overgegaan tot vaccinatie van de moederdieren met toxoïd vaccins die het bètatoxine bevatten om op die manier de kalveren te beschermen via passieve immuniteit. Hoewel er geen studies konden worden gevonden over de efficiëntie van de vaccinatie voor deze specifieke indicatie worden door practici ook hier vaak goede resultaten gemeld.

\section{Hemorragische abomasitis bij neonatale kalveren}

\section{Klinische bevindingen}

Deze aandoening leunt sterk aan bij necrotische enteritis en kan er niet altijd van onderscheiden worden. De ziekte gaat gepaard met anorexie, opzetting van het abdomen, regurgitatie, ernstige depressie en shock. De dieren vertonen een bloederige lebmaaginhoud en een necro-hemorragische ontsteking van de lebmaagmucosa die vaak gepaard gaat met emfyseem van de wand (Songer en Miskimins, 2005).

\section{Pathogenese}

In tegenstelling tot necrotische enteritis wordt deze ziekte niet geassocieerd met het bètatoxine maar met een klonale overgroei van type A-stammen. Deze stammen produceren enkel het alfatoxine en geen van de andere "major toxines". Over de verdere pathogenese van deze aandoening is zeer weinig bekend (Manteca et al., 2001; Songer en Miskimins, 2005; Van Kruiningen, 2009). Algemeen wordt aangenomen dat het gebrek aan een competitieve flora en de lage endogene productie van enzymen bij neonatale kalveren bijdragen tot deze aandoening. Bovendien kan het toedienen van grote hoeveelheden colostrum in één voederbeurt, bijvoorbeeld via sondage, leiden tot een uitzetting van de lebmaag, waardoor de $\mathrm{pH}$ daling, de stremming van het colostrum en het legen van de lebmaag vertraagd worden, wat kan predisponeren voor bacteriële overgroei.

\section{Diagnose en bestrijding}

De diagnose wordt meestal gebaseerd op het klinisch verloop van de ziekte en op autopsiebevindingen, eventueel aangevuld met resultaten van het histologisch onderzoek. Aangezien de ziekte geassocieerd wordt met type A-stammen, die een normaal onderdeel zijn van de gastro-intestinale flora, is bacteriologisch onderzoek of toxinedetectie, net zoals voor enterotoxemie, van zeer weinig waarde voor de diagnose van deze aandoening bij oudere kalveren (Valgaeren et al., 2013b).

Gezien de ziekte zeer moeilijk te onderscheiden is van bètatoxine-gemedieerde necrotische enteritis, ligt ook de preventie in dezelfde lijn. Bijkomend wordt een hygiënische verschaffing van colostrum met adequate reiniging en desinfectie van het materiaal uitermate belangrijk geacht wanneer grote hoeveelheden biest in één keer worden verschaft (Valgaeren et al., 2015a).

\section{CONCLUSIE}

C. perfringens kan verschillende types gastrointestinale ontstekingen veroorzaken, waarbij het ziektebeeld voornamelijk afhankelijk is van de leeftijd van het dier en de geproduceerde toxinen. Overvoedering met structuurarme, eiwitrijke voeders blijkt een gemeenschappelijke risicofactor te zijn bij al deze aandoeningen. Een goed uitgebalanceerd dieet dat zo stabiel mogelijk gehouden wordt, is dan ook het belangrijkste aandachtspunt op bedrijven die problemen hebben met clostridiose. Daarnaast dient bij jonge kalveren voldoende aandacht gegeven te worden aan een correcte en hygiënische biestverstrekking om problemen met neonatale clostridiose te vermijden. 


\section{LITERATUUR}

Abutarbush S.M., Carmalt J.L., Wilson D.G., O'Connor B.P., Clark E.G., Naylor J.M. (2004). Jejunal haemorhage syndrome in 2 Canadian beef cows. Canadian Veterinary Journal 45, 48-50

Abutarbush S.M., Radostits O.M. (2005). Jejunal haemorrhage syndrome in dairy and beef cattle: 11 cases (20012003). Canadian Veterinary Journal 46, 711-715

Aichelman W.W., Griner L.A., Brown G.D. (1956). Clostridium perfringens type D (ETX) enterotoxaemia in brown Swiss dairy calves. Journal of American Veterinary Medicine 140, 154-158

Annett C.B., Viste J.R., Chirino-Trejo M., Classen H.L., Middleton D.M., Simko E. (2002). Necrotic enteritis: effect of barley, wheat and corn diets on proliferation of Clostridium perfringens type A. Avian Pathology 31, 598-601

Atkinson P.N. (1998). Clostridium perfringens type D in a dairy cow. Veterinary Record 142(5), 120

Bains D., Erb S., Turkington K., Kuldau G., Juba J., Masson L., Mazza A., Robers R. (2011). Mouldy feed, mycotoxins and shiga toxin-producing Escherichia Coli colonization associated with jejunal haemorrhage syndrome in beef cattle. BMC Veterinary Journal 7, 24

Barker I.K., van Dreumel A.A., Palmer N. (1993). The alimentary system, disease associated with enteric clostridial infection. In: Jubb V.F., Kennedy P.C., Palmer N. (editors). Pathology of Domestic Animals. 5de Ed., vol. 2, Academic Press, New York, p. 213-221

Berghaus R.D., McCluskey B.J., Callan R.J. (2005). Risk factors associated with haemorrhagic bowel syndrome in dairy cattle. Journal of the American Veterinary Medical Association 226, 1700-1706

Ceci L., Paradies P., Sasanelli M., De Caprariis D., Guarda F., Capucchio M.T., Carelli G. (1998). Haemorrhagic bowel syndrome in dairy cattle: possible role of Clostridium perfringens type A in the disease complex. Journal of Veterinary Medicine Series A 53, 518-523

Collado M.C., Sanz Y. (2007). Induction of acid resistance in Bifidobacterium: a mechanism for improving desirable traits of potentially probiotic strains. Journal of Applied Microbiology 103(4), 1147-1157

Doyle E. (2002). Survival and growth of Clostridium perfringens during the cooling step of thermal processing of meat oroducts. FRI briefing, Food Research Institute.

Elhanafy M.M., French D.D., Braun U. (2013). Understanding jejunal haemorrhage syndrome. Journal of the American Veterinary Medical Association 243, 352-358

Filho E.J., Carvalho A.U., Assis R.A., Lobato F.F., Rachid M.A., Carvalho A.A., Ferreira P.M., Nascimento R.A., Fernandes A.A., Vidal J.E., Uzal F.A. (2009). Clinicopathologic features of experimental Clostridium perfringens type D enterotoxemia in cattle. Veterinary Pathology 46(6), 1213-1220

Forsberg N. (2003). New findings on jejunal haemorrhagic syndrome. Hoard's Dairyman 148, 311

Fuchs R., Bonde G. (1957). The nutritional requirements of Clostridium perfringens. Journal of Genetic Microbiology 16, 317-329

Garcia J.P., Beingesser J., Fisher D.J. (2012). The effect of Clostridium perfringens type C strain CN3685 and its isogenic beta toxin null mutant in goats. Veterinary Microbiology 157, 412-418
Garcia J.P., Anderson M., Blanchard P., Mete A., Uzal F.A. (2013). The pathology of enterotoxaemia by Clostridium perfringens type $\mathrm{C}$ in calves. Journal of Veterinary Diagnostic Investigation 25, 438

Glock R.D., DeGroot B.D. (1998). Sudden death of feedlot cattle. Journal of Animal Science 76, 315-319

Godden S., Frank R., Ames T. (2001). Survey of Minnesota dairy veterinarians on the occurrence of and potential risk factors for haemorrhage syndrome in adult dairy cows. The Bovine Practitioner 35, 97-103

Goossens E., Verherstraeten S., Valgaeren B., Pardon B., Timbermont L., Schauvliege S., Rodrigo-Mocholi D., Haesebrouck F., Ducatelle R., Deprez P., Van Immerseel F. Toxin-neutralizing antibodies protect against $C$. perfringens-induced necrosis in an intestinal loop model for bovine enterotoxaemia. (In preparation)

Griesemer R.A., Krill W.R. (1962). Enterotoxaemia in beef calves - 30 years observation. Journal of the American Veterinary Medical Association 140, 154-158

Griner L.A., Brackken E.K. (1953). Clostridium perfringens (type C) in acute haemorrhagic enteritis in calves. Journal of the American Veterinary Medical Association 122, 99-102

Hasan S.M., Hall J.B. (1975). The physiological function of nitrate reduction in Clostridium perfringens. Journal of Genetic Microbiology 87(1), 120-128

Hatheway C.L. (1990). Toxigenic Clostridia. Clinical Microbiology Reviews 3(1), 66-98

Hurst L.D., Merchant A.R. (2001). "High guanine-cytosine content is not an adaptation to high temperature: a comparative analysis amongst prokaryotes". Processed Biology Science 268 (1466), 493-497

Jimoh A., Ibitoye E., Dabai Y., Garba S. (2013). In vivo antimicrobial potentials of garlic against Clostridium perfringens and its promotant effects on performance of broiler chickens. Pakistanian Journal of Biology Science 16(24), 1978-1984

Keast J.C., McBarron E.J. (1954). A case of bovine enterotoxaemia. Australian Veterinary Journal 56, 305-306

Keyburn A.L., Bannam T.L., Moore R.J., Rood J.I. (2010). NetB, a pore-forming toxin from necrotic enteritis strains of Clostridium perfringens. Toxins (Basel) 2(7), 19131927

Kirkpatrick M.A., Timms L.L., Kersting K.W., Kinyon J.M. (2001). Jejunal haemorrhage syndrome of dairy cattle. Bovine Practitioner 35, 104-116

Lebrun M., Mainil J.G., Linden A. (2010). Cattle enterotoxaemia and Clostridium perfringens: description, diagnosis and prophylaxis. Veterinary Record 167, 13-22

Lee S.H., Lillehoj H.S., Jang S.I., Lillehoj E.P., Min W., Bravo D.M. (2013). Dietary supplementation of young broiler chickens with Capsicum and turmeric oleoresins increases resistance to necrotic enteritis. British Journal of Nutrition 110(5), 840-847

Manteca C., Daube G., Pirson V., Limbourg B., Kaeckenbeeck A., Mainil J.G. (2001). Bacterial intestinal flora associated with enterotoxaemia in Belgian Blue calves. Veterinary Microbiology 81(1), 21-32

Manteca C., Daube G., Jauniaux T., Linden A., Pirson V., Detilleux J., Ginter A., Coppe P., Kaeckenbeeck A., Mainil J.G. (2002). A role for the Clostridium perfringens beta2 toxin in bovine enterotoxaemia? Veterinary Microbiology 86(3), 191-202

Muylaert A., Lebrun M., Duprez J.N., Labrozzo S., Theys 
H., Taminiau B., Mainil J. (2010). Enterotoxaemia-like syndrome and Clostridium perfringens in veal calves. Veterinary Record 167, 64-65

Niilo L., Moffat R.E., Avery R.J. (1963). Bovine enterotoxaemia II: experimental reproduction of the disease. Canadian Veterinary Journal 4, 288-297

Niilo L., Harris W.N., Jones G.A. (1974). Clostridium perfringens type $\mathrm{C}$ in haemorrhagic enterotoxaemia of neonatal calves in Alberta. Canadian Veterinary Journal 15, 224-226

Niilo L. (1980). Clostridium perfringens in animal disease: a review of current knowledge. Canadian Veterinary Journal 21(5), 141-148

Orsburn B., Melville S.B., Popham D.L. (2008). Factors contributing to heat resistance of Clostridium perfringens endospores. Applied Environmental Microbiology 74(11), 3328-3335

Paredes-Sabja D., Torres J.A., Setlow P., Sarker M.R. (2008). Clostridium perfringens spore germination: characterization of germinants and their receptors. Journal of Bacteriology 190(4), 1190-1201

Pardon B., De Bleecker K., Hostens M., Callens J., Dewulf J., Deprez P. (2012). Longitudinal study on morbidity and mortality in white veal calves in Belgium. BMC Veterinary Research 8, 26

Shimizu T., Ohtani K., Hirakawa H., Ohshima K., Yamashita A., Shiba T., Ogasawara N., Hattori M., Kuhara S., Hayashi H. (2002). Complete genome sequence of Clostridium perfringens, an anaerobic flesh-eater. In: Proceeding of the National Academy of Science USA 99(2), 996-1001

Socket D.C. (2004). Haemorrhagic bowel syndrome. In: Proceedings of the 2nd Mid-Atlantic Nutrition Conference, Timonium, USA, 139-145

Songer G. (1996). Clostridial enteric diseases of domestic animals. Clinical Microbiology reviews 9(2), 216-234

Songer G., Miskimmins D. (2004). Clostridium perfringens type E enteritis in calves: two cases and a brief review of the literature. Anaerobe 10, 239

Troxel T.R., Burke G.L., Wallace W.T., Keaton L.W., McPeake S.R., Smith D., Nicholson I. (1997). Clostridial vaccination efficacy on stimulating and maintaining an immune response in beef cows and calves. Journal of Animal Science 75(1), 19-25

Valgaeren B., Pardon B., Goossens E., Verherstraeten S., Schauvliege S., Timbermont L., Ducatelle R., Deprez P., Van Immerseel F. (2013a). Lesion development in a new intestinal loop model indicates the involvement of a shared Clostridium perfringens virulence factor in haemorrhagic enteritis in calves. Journal of Comparative Pathology 149, 103-112

Valgaeren B., Pardon B., Verherstraeten S., Goossens E., Timbermont L., Haesebrouck F., Ducatelle R., Deprez P., Van Immerseel F. (2013b). Intestinal clostridial counts have no diagnostic value in the diagnosis of enterotoxaemia in veal calves. Veterinary Record 172(9)

Valgaeren B., Pardon B., Verherstraeten S., Goossens E., Timbermont L., Haesebrouck F., Ducatelle R., Van Immerseel F., Deprez P. (2015a). Haemorrhagic enteritis in new-born calves associated with Clostridium perfringens and colostrum delivery. JMM Case Reports, In press

Valgaeren B., Pardon B., Goossens E., Verherstraeten S., Roelandt S., Timbermont L., Van Der Vekens N., Stuyvaert S., Gille L., Van Driessche L., Haesebrouck F., Ducatelle R., Van Immerseel F., Deprez P. (2015b). Veal calves produce less antibodies against $C$. Perfringens alpha toxin compared to beef calves. Toxins 7(7), 2586-2597

Van Kruiningen H.A., Nyaoke C.A., Lindell K.A. (2009). Clostridial abomasal disease in Connecticut dairy calves. Canadian Veterinary Journal 50(8), 857-860

Verherstraeten S., Goossens E., Valgaeren B., Pardon B., Timbermont L., Vermeulen K., Schauvliege S., Haesebrouck F., Ducatelle R., Deprez P., Van Immerseel F. (2013). The synergistic necrohaemorrhagic action of Clostridium perfringens perfringolysin and alpha toxin in the bovine intestine and against bovine endothelial cells. Veterinary Research 19, 44-45

Worrall E.E., Natalia L., Ronohardjo F., Partoutomo S., Tarmudji V. (1987). Enterotoxaemia in water buffaloes caused by Clostridium perfringens type A. Veterinary Record 121, 278-279 